\title{
MANIFESTAÇÕES BRASILEIRAS E O MOVIMENTO VEM PRA RUA: BREVE ANÁLISE DOS ACONTECIMENTOS ${ }^{1}$ Brazilian manifestations and the Vem Pra Rua movement: brief analysis of events
}

\author{
Vinícius de Souza STURARI \\ Universidade Estadual Paulista "Júlio de Mesquita Filho" - UNESP, Araraquara, Brasil \\ v.sturari@gmail.com \\ (1) https://orcid.org/0000-0003-0727-770X
}

Mais informações sobre a obra no final do artigo

\begin{abstract}
RESUMO
A intensificação de manifestações de rua e em rede nos últimos anos marca uma mudança nos padrões de participação política. No Brasil, grandes manifestações eclodiram em 2013 e 2015, com demandas diferentes, mas em comum a forma de organização: prioritariamente por meio da internet. Essa nova dinâmica participativa traz novos atores, movimentos sociais que usam a internet para sua organização. Dentre eles destacamos o Vem Pra Rua, um dos principais articuladores das manifestações de 2015, criado por dois empresários paulistas e que conquistou grande apoio de famosos e políticos. Nesse artigo fizemos um retrospecto das manifestações brasileiras elencando o papel do movimento Vem Pra Rua nos atos mais recentes. A metodologia adotada constituiu um levantamento bibliográfico sobre o tema, bem como coleta de dados nas redes sociais e publicações sobre o movimento. Percebemos, conforme demonstramos, o importante papel da internet na organização dos atos enquanto um mecanismo que proporciona inovações e mudanças nos padrões de participação política e como os novos movimentos sociais utilizaram esse mecanismo para isso.
\end{abstract}

PALAVRAS-CHAVE: Manifestações. Movimentos de Rede. Vem Pra Rua. Internet.

\begin{abstract}
The intensification of street and network demonstrations in recent years marks a change in patterns of political participation. In Brazil, major demonstrations broke out in 2013 and 2015, with different demands, but in common the form of organization: primarily through the internet. This new participatory dynamic brings new actors, social movements that use the internet for their organization. Among them we highlight Vem Pra Rua, one of the main organizers of the 2015 demonstrations, created by two businessmen from São Paulo which gained great support from celebrities and politicians. In this article we made a retrospective of the Brazilian demonstrations, listing the role of the Vem Pra Rua movement in the most recente acts. The chosen methodology constituted a bibliographic survey on the theme, as well as data collection on social networks and publications about the movement. We perceive, as we have shown, the important role of the internet in the organization of acts as a mechanism that provides innovations and changes in patterns of political participation and how the new social movements used this mechanism for that.
\end{abstract}

KEYWORDS: Manifestations. Networks Movements. Vem Pra Rua. Internet.

\footnotetext{
1 O presente artigo contém partes do trabalho apresentado no I Seminário de Sociologia e Política da UFSC, bem como algumas reflexões iniciais de minha Dissertação de mestrado e foi financiado pela Coordenação de Aperfeiçoamento de Pessoal de Nível Superior (CAPES).
} 


\section{INTRODUÇÃO}

Este artigo contém partes de um trabalho apresentado no I Seminário de Sociologia e Política da UFSC, em setembro de 2018, e se insere em algumas discussões propostas em minha Dissertação de mestrado, em fase inicial na época. Agradeço aos debatedores e colegas do Grupo de Trabalho pelas contribuições e debates. Neste artigo o intuito é trazer algumas reflexões sobre o papel da internet e do movimento Vem Pra Rua nos protestos de 2015 e 2016 no Brasil. Em muitos momentos utilizo como referência o livro escrito pelos fundadores do movimento que relata a história do mesmo, como forma de trazer a visão dos participantes sobre os fatos e dar voz a esses atores.

Para entender as manifestações de 2015 e 2016 no Brasil devemos retomar a histórico desse repertório nos anos que as antecedem, contextualizando seu uso no Brasil e no mundo. As manifestações ocorridas no ano de 2013 no Brasil, que ficaram conhecidas como Jornadas de Junho, se tornaram um ponto essencial para pensar sobre participação democrática, tendo como uma das explicações sobre o porquê do ciclo de protestos iniciado naquela época ter sido continuado, a insatisfação pública em relação aos políticos e instituições políticas. O conceito de ciclo de protestos é definido por Tarrow, segundo Tatagiba (2014, p. 37), como

uma fase de intensificação dos conflitos, no qual um conjunto diversificado de atores toma parte em manifestações públicas coletivas em ritmo e intensidade superiores ao verificado regularmente, difundindo-se rapidamente dos setores mais mobilizados para os menos mobilizados.

O cenário político mundial em tempos que precedem as Jornadas de Junho é de manifestações e protestos ${ }^{2}$. Um espectro de crise política mundial e possível consequência da crise financeira de 2008 ronda até mesmo as democracias mais consolidadas, como o caso dos Estados Unidos. Castells (2013) faz uma análise desses acontecimentos e propõe o surgimento de movimentos de rede, movimentos sociais surgidos e organizados a partir da internet. Isso é um reflexo do que o autor chama de sociedade de rede (Id., 2003), e afirma que "cada vez mais, as pessoas estão organizadas não simplesmente em redes

\footnotetext{
${ }^{2} \mathrm{O}$ debate teórico e metodológico acerca do uso desses termos é antigo e ganha força após as Jornadas de Junho no Brasil. Essas manifestações trouxeram à tona um fenômeno social sem precedentes na história do país principalmente por suas características, como o uso da internet e redes sociais para organização dos atos, movimentos sociais que se utilizam desse meio como modus operandi, dentre outras coisas, debate que não pretendo trazer nesse artigo por suas complexidades. Para mais informações ver Gohn (2016).
} 
sociais, mas em redes sociais mediadas por computador" (CASTELLS, 2003, p. 109). O autor ainda completa que

Uma vez que a internet está se tornando um meio essencial de comunicação e organização em todas as esferas de atividade, é óbvio que também os movimentos sociais e o processo político a usam, e o farão cada vez mais, como um instrumento privilegiado para atuar, informar, recrutar, organizar, dominar e contradominar (CASTELLS, 2003, p.114)

Além de usarem a internet como maneira de organização e divulgação, as manifestações recentes em diversos países têm em comum crises financeiras e políticas. Segundo Castells "cada revolução tem sua data de nascimento e seu herói rebelde" (2013, p. 39), ou seja, o causador do estopim que leva diversas pessoas às ruas, com o sentimento de indignação. Esse é o sentimento que faz os indivíduos superarem o medo e partirem para a ação, segundo o autor. "E eles superam o medo pela expressão extrema da raiva, sob a forma de indignação, ao tomarem conhecimento de um evento insuportável ocorrido com alguém com quem se identificam" (CASTELLS, 2013, p. 23).

$\mathrm{Na}$ Tunísia, um vendedor ambulante, cansado de ter sua banca de frutas apreendida pela polícia local por se recusar a pagar propina ateia fogo em si na frente de um prédio do governo. Sua ação é filmada e viraliza na internet, fazendo surgir outras insurreições pelo país. Na Islândia, um músico se senta na frente do parlamento e expressa seu ódio aos políticos cantando. Vendo isso mais algumas pessoas se juntam a ele e são filmadas e, após alguns dias, muitas outras acompanham tocando panelas e outros diversos aparatos que usam como instrumentos ocasionando uma pressão que acaba adiantando as eleições do país. Essas duas primeiras situações descritas, Castells (2013) cita como antecessoras às ações dos movimentos em rede, pois foram organizadas por civis sem vínculos com movimentos ou outras instituições, sendo propagadas através da internet.

Nas manifestações posteriores entram em cena movimentos sociais organizados, que utilizam da estratégia de divulgação na internet, alcançando maior público e chamando as pessoas à ação. A rede proporciona a divulgação de um vídeo postado por uma participante de um movimento organizado chamando manifestantes a ocupar a praça Tahrir, no Egito, informando que seis pessoas tiveram a mesma atitude que o comerciante da Tunísia e atearam fogo ao próprio corpo. A partir disso várias manifestações se espalham pelo Egito e dão início à Primavera Árabe, ciclo de protestos com diversas manifestações que ocorrem em países árabes, sendo alguns deles: Argélia, Líbano, Jordânia, Mauritânia, Sudão, Omã, lêmen, Bahrein, Líbia, Kuwait, Marrocos, com os atos divulgados pela internet, 
repreendidos em maioria por forças militares de seus respectivos governos e ocasionando até mesmo guerras civis em alguns casos.

$\mathrm{Na}$ Espanha, o movimento dos indignados, civis que ocuparam praças de diversas cidades e montaram acampamento, o Ocuppy Wall Street, que consistia em acampamentos em Wall Street, rua que é um dos centros financeiros dos Estados Unidos local em que funciona a Bolsa de Nova lorque e diversas outras empresas. É nesse contexto global de manifestações desde 2011 que se encontram as Jornadas de Junho, no Brasil, que dão início a um ciclo de protestos que se estende até 2016, como trabalharemos a seguir.

Este artigo conta com outras três partes além dessa breve introdução. Na próxima parte falaremos sobre os precursores das manifestações organizadas pelo Vem Pra Rua entre 2014 e 2016, o Movimento Passe Livre e as Jornadas de Junho. No item seguinte discutiremos sobre o movimento Vem Pra Rua em si e as manifestações que ele organizou, com teor anticorrupção. Cabe aqui um parênteses para explicar a escolha por esse movimento: ela se deu pela centralidade dele nas manifestações do período entre o fim de 2014 e meio do ano de 2016, que elencamos aqui, uma vez que, conforme apontado por Tatagiba, Trindade e Teixeira (2015, p. 199), esse movimento foi responsável pela organização da maioria das manifestações deste período (No texto os autores elaboraram um quadro que elenca manifestações no período de julho de 2007 a agosto de 2015, neste artigo consideraremos as informações a partir de 2014 e vamos um pouco além, até 2016), bem como a possibilidade de utilizar fonte primária para coleta dos dados, pois os fundadores do movimento escreveram um livro relatando a história de sua organização.

Por fim, traremos alguns apontamentos e reflexões acerca do que foi discutido. Metodologicamente realizamos um levantamento e revisão bibliográfica sobre o tema, além de coletar informações sobre os movimentos aqui abordados nas redes sociais e sites dos mesmos, sendo que sobre o Vem Pra Rua utilizamos ainda o livro escrito por seus fundadores.

\section{AS PRIMEIRAS MANIFESTAÇÕES (2013)}

Conforme aponta Gohn (2016, p. 129) "A partir de 2013 novíssimos atores entraram em cena e mudaram o panorama das manifestações no Brasil com multidões nas ruas após serem convocadas por redes sociais on-line". Tatagiba e Galvão (2019) analisaram eventos de protestos de 2011 a 2016 e percebem que os protestos seguem uma trajetória oscilante 
nesse período. Crescem entre 2011 e 2012 cerca de 140\%, "o que sugere que o caldeirão de insatisfações que explode em 2013 já estava aquecendo desde o ano anterior" (Ibid., p. 70). As autoras demonstram ainda que ocorre um declínio em 2014 e a curva volta a crescer em 2015, mas sobre esse segundo período falaremos mais adiante.

Os primeiros protestos de 2013 foram organizados pelo Movimento Passe Livre (MPL), no mês de junho. O MPL [s.d] se considera "apartidário, horizontal e independente", cuja organização não possui lideranças e as decisões são tomadas em assembleias, com principal pauta o direito à cidade, através de uma livre circulação, "luta por um transporte público de verdade, gratuito para o conjunto da população e fora da iniciativa privada". As manifestações iniciais ocorreram na cidade de São Paulo, sendo chamadas pelas redes sociais, e tiveram pouca adesão, com cerca de dois a cinco mil participantes (SINGER, 2013; SECCO, 2013). Esses atos foram repudiados pela mídia (ROMÃO, 2014; LIMA, 2013), que os caracterizou como violentos, atribuindo a culpa ao MPL sobre depredações ocorridas durante as manifestações e que foram feitas por pequenos grupos de pessoas não ligadas ao movimento.

A quarta manifestação ocorre no dia 13 de junho, sendo severamente reprimida pela Polícia Militar paulistana, que faz uso desmedido da força para conter os manifestantes que se aglomeravam na região central da cidade, próximos à Avenida Paulista, e se torna o estopim dos acontecimentos seguintes, o fator que desencadeia o que Singer (2013) define como a "segunda etapa do movimento".

A manifestação que ocorre quatro dias depois, em 17 de junho, leva milhares de pessoas às ruas, uma multidão que se solidarizou com os manifestantes que sofreram com a ação desmedida da polícia e vai às ruas, contribuindo com o movimento mas ao mesmo tempo tornando vagas as demandas, conforme afirma Singer (2013), pois nesse momento entram em pauta os mais diversos assuntos, como Rolnik (2013, p. 8) afirma: "no decorrer dos protestos houve uma disputa nos cartazes empunhados pelo conjunto heterogêneo que ocupou as ruas e uma guerra de interpretações das vozes rebeldes".

A ação desmedida e violenta da polícia, fator que segundo Yoruk (2013), leva multidões à praça de Gezi, na Turquia, é o mesmo detonador das manifestações no Brasil ${ }^{3}$, dando maior visibilidade a elas, pois nesse momento a mídia se voltou para as manifestações, transmitiu imagens da ação policial e até mesmo interrompeu sua programação normal para noticiar as ruas (ROMÃO, 2014; LIMA, 2013). Após esses

3 Ver: Singer (2013), Tatagiba (2013), Yoruk (2013), Rolnik (2013), Secco (2013), Sakamoto (2013), Alzamorra, Arce e Utsch (2014), Pessoa (2014), Souza (2016). 
acontecimentos, nessa segunda etapa as manifestações se espalharam por diversas capitais do país, com as mais diversas reivindicações, o que Singer (2013) coloca como "cada pessoa um cartaz", e que Tatagiba (2014, p. 58) diz ser uma "expressão eloquente da crise de representação das democracias contemporâneas". Sobre isso ainda, Bringel e Pleyers (2015, p. 7-8) afirmam que

Uma vez aberto o espaço de protesto pelas mobilizações iniciais, outros atores se uniram para fazer suas próprias reivindicações, sem necessariamente manter os laços com as mobilizações originais e repetir as formas, a cultura organizacional, as referências ideológicas ou os repertórios de ação dos iniciadores essas mobilizações. [...] Nesse momento, ao emergir um novo ciclo de protestos, presenciou-se um transbordamento societário, isto é, um momento em que o protesto se difunde dos setores mobilizados para outras partes da sociedade, transbordando os movimentos sociais que o iniciaram.

Gohn (2016, p. 129) afirma que as manifestações retomam problemas da vida cotidiana como "mobilidade urbana, emprego, finanças/salário, dívidas, serviços sociais como educação e saúde, moradia popular, terra para viver e plantar (demanda já secular, agora em confronto com o agronegócio e outros) etc". Além dessas, ecoam denúncias sobre a precariedade dos serviços públicos (GOHN, 2016), com fortes brados de quem é contra os mega eventos esportivos que ocorrerão no país e demandam um grande investimento de dinheiro público, quando muitos serviços públicos sofrem corte ou falta de verbas e são sucateados. Pessoas empunhavam cartazes dizendo

"Copa do Mundo eu abro mão, quero dinheiro pra saúde e educação", "Queremos hospitais padrão Fifa", "O gigante acordou", "la ixcrever augu legal, maix fauto edukssao", "Não é mole, não. Tem dinheiro pra estádio e cadê a educação", "Era um pais muito engraçado, não tinha escola, só tinha estádio", "Todos contra a corrupção", "Fora Dilma! Fora Cabral! PT = Pilantragem e traição", "Fora Alckmin", "Zé Dirceu, pode esperar, tua hora vai chegar", foram algumas das inúmeras frases vistas nas cartolinas. (SINGER, 2013, p. 25).

Além disso, os escândalos sobre corrupção no país, recentes na época, tanto no governo federal e tendo foco no Partido dos Trabalhadores (PT), ao qual a presidente Dilma Rousseff é vinculada, como em governos estaduais, traz à tona também a pauta anticorrupção, que norteará as manifestações em 2015 e 2016, como veremos adiante. Vozes bradavam que "não é por centavos, é por direitos" (ROMÃO, 2014, p.159), o que é contestado por Tatagiba (2014), devido à diminuição dos atos após a revogação do aumento da tarifa, contando ainda com a saída do MPL das manifestações, que foram se 
enfraquecendo pelo estado de São Paulo e pelo país, no que Gohn (2016, p. 136) afirma "logo após Junho de 2013, as manifestações não tiveram continuidade em termos de mobilização de massa, os atos de protestos foram tópicos, com focos específicos [...]", como Romão (2014) cita sobre Rio de Janeiro e Belo Horizonte, cidades em que ocorreram protestos contra a Copa das Confederações e algumas outras ações políticas locais.

Como afirma o jornalista Leonardo Sakamoto (2013) no título de seu texto: "o Facebook e o Twitter foram às ruas", afinal, "movimentos animados por redes não precisam ser prisioneiros do universo virtual. Podem agir no mundo concreto" (NOGUEIRA, 2013, p. 56). É através da internet que os atos são organizados ${ }^{4}$ e essa característica é um diferencial de protestos organizados anteriormente no país, conforme vemos em Tatagiba (2014) e Gohn (2016), sendo isso reflexo da nova sociedade de rede apontada por Castells (2003), e principal meio de organização dos protestos, pois é na internet que os atos são divulgados e as pessoas são chamadas à comparecer, é o que faz desse novo ciclo de protestos uma modalidade de participação a ser estudada.

As manifestações da segunda fase, com forte demanda anticorrupção, já trazem prenúncios das futuras manifestações de 2015 e 2016, que possuem um teor nacionalista e antipetista, conforme afirma Souza C. (2016). Sakamoto (2013, p. 97) aponta sobre a participação de manifestantes "com um discurso superficial, que cola fácil [...] Parte usava o verde-amarelo, lembrando os divertidos e emocionantes dias com os amigos em que se podem ver os jogos da Copa do Mundo". Souza (2016, p. 91) diz que:

Começava a criação estética e moral do movimento antigoverno federal, capitaneado pela grande imprensa: os ritos passaram a ser cantar o hino nacional, vestir a camisa da seleção, ter a cara pintada e usar a bandeira nacional. Mudaram não apenas as bandeiras iniciais do movimento, mas também o público que as apoiava. Em vez de jovens e estudantes, tínhamos agora famílias de classe média com perfil de renda alta.

E ainda complementa: "A manifestação perdia seu sentido popular e reivindicativo e se tornava uma 'festa popular' contra a corrupção e a ladroagem na política, o que se tornava definitivamente a bandeira central" (SOUZA, p. 93).

\footnotetext{
4 Ver: Singer (2013), Tatagiba (2014), Rolnik (2013), Secco (2013), Sakamoto (2013), Alzamorra, Arce, e Utsch (2014), Pessoa (2014), Souza (2016) e Nogueira (2013).
} 


\section{NOVA FASE DE PROTESTOS (2014-2016)}

Conforme já vimos, o MPL saiu de cena assim que o aumento da tarifa foi revogado pelo prefeito da cidade de São Paulo e governador do mesmo estado, Fernando Haddad e Geraldo Alckmin, conforme aponta Tatagiba (2014), o que causou a diminuição da frequência de manifestações em 2013. Porém, como apontamos anteriormente, houve um transbordamento societário (BRINGEL, PLEYERS, 2015) e deixando, desde o fim das Jornadas de Junho, uma forte demanda anticorrupção, trazendo novos atores e novas manifestações, "com características totalmente diferentes das de Junho de 2013, pelo repertório das demandas, grupos sociais que as convocam, composição social e de faixa etária dos participantes" (GOHN, 2016, p. 138).

Alonso e Mische (2017) identificaram três tipos de repertórios presentes nesse ciclo de protestos (2013-2016), sendo eles o repertório socialista, "velho conhecido, reapareceu em bandeiras vermelhas, megafones, organização vertical" (ALONSO, 2017, p. 49). O segundo repertório é o autonomista, que tem como base um estilo anti-hierarquia de gênero, organização descentralizada, deliberação por consenso, contra símbolos dos poderes financeiro e político (ALONSO, MISCHE, 2017; ALONSO, 2017), esse repertório foi uma novidade das manifestações de 2013. Já o último repertório, o patriota, teve grande utilização desde o fim das Jornadas de Junho, quando os manifestantes iam às ruas com camisas verde e amarelo, bandeiras do Brasil e cantavam o hino nacional no fim dos atos, sendo o principal repertório nas manifestações de 2014 a 2016.

No fim do ano seguinte às Jornadas de Junho, em 2014, pouco antes das eleições no mês de outubro, outras manifestações começam a ganhar corpo em uma nova fase de manifestações que se estende até 2016. Nesse período entraram em cena outros movimentos, sendo os principais nessa fase e com maior visibilidade nas redes e nas ruas: Movimento Brasil Livre (MBL) e Vem Pra Rua, sobre os quais falaremos a seguir.

Na página do MBL ([s.d.]) na rede social Facebook, encontramos a seguinte definição: "o MBL - Movimento Brasil Livre - é uma entidade sem fins lucrativos que visa mobilizar cidadãos em favor de uma sociedade mais livre, justa e próspera". As bandeiras do MBL são a Democracia, a República, a Liberdade de Expressão e de Imprensa, o Livre Mercado, a Redução do Estado, Redução da Burocracia.

Já o Vem Pra Rua ([s.d.]), nosso foco nesse artigo conforme explicado na introdução, traz como definição do movimento, em seu site: "O Vem Pra Rua é um movimento suprapartidário, democrático e plural que surgiu da organização espontânea da sociedade 
civil em 2014". E coloca como principal bandeira "O Vem Pra Rua quer um Brasil livre da corrupção, com uma política feita com ética e um Estado desinchado e eficiente, verdadeiramente democrático e justo". Podemos ver essa afirmação das pautas também em seu Manifesto (VEM PRA RUA, [s.d.]) no site, que afirma:

Somos a favor da democracia, da ética na política e de um Estado eficiente e desinchado. Somos contra qualquer tipo de violência e condenamos qualquer tipo de extremismo (separatismo, intervenção militar, golpe de Estado), e não compactuamos com governos autoritários.

O Vem pra Rua foi criado por Rogério Chequer e Colin Butterfield, "ligados ao mundo financeiro e empresarial, de modo que muitos de seus pronunciamentos públicos advogam a defesa da incorporação da gestão empresarial ao mundo da política" (GARCIA, LOPES, 2017, p. 9).

Os dois fundadores do movimento se conheceram por meio de um amigo em comum, que os apresentou pelo fato de ambos terem ideias semelhantes e sonharem com um Brasil melhor, conforme afirmam no livro que escreveram sobre a história do movimento, intitulado "Vem Pra Rua: a história do movimento popular que mobilizou o Brasil". Segundo os fundadores, eles estavam indignados com a situação atual do país. Citam no livro ainda que poderiam simplesmente deixar o Brasil e ir morar em qualquer outro país inclusive, não dar a cara a tapa em rede nacional.

Mas nós estávamos indignados o bastante para, inicialmente, andar na contramão. Inicialmente. O que não esperávamos - embora buscássemos - era encontrar tantos outros indignados dispostos a tomar a mesma atitude. Indignados a ponto de topar fazer algo diferente do que haviam feito (ou deixado de fazer) ao longo da vida inteira. Indignados a ponto de se mexer e tomar a responsabilidade para si. Indignados que se tornaram inconformados e que se levantaram do confortável sofá em que assistem diariamente ao jornal para protagonizar o noticiário (CHEQUER, BUTTERFIELD, 2016, p. 10).

Tida a ideia de fazer algo a respeito, Chequer e Butterfield (2016, p. 21) atentam que no princípio, ambos pensaram o movimento como um "Basta", título do projeto inicial e que teria "[...] as mídias sociais como cerne do movimento [...]". Marcaram uma manifestação do "Basta" e divulgaram nas mídias sociais, porém apenas quatro pessoas (Chequer e outros três amigos) apareceram, o que para eles significou um fracasso da tentativa. Após o acontecido, Chequer conta no livro que conversou com alguns outros amigos e decidiu, junto com Collin, a mudar a postura e a tática utilizadas. Pensando quem estaria indignado com a situação também, decidiram por convidar suas redes de contatos para ir às ruas. 
Naquele momento a estratégia parecia óbvia. E as redes sociais, o melhor canal. Afinal, elas intuitivamente podem ser utilizadas para esse fim. Uma pessoa cria um evento e convida seu grupo de amigos. Esses amigos, por sua vez, podem facilmente chamar os próprios amigos $\mathrm{E}$, assim, o convite se cascatearia rapidamente (CHEQUER, BUTTERFIELD, 2016, p. 36)

E completam:

O passo seguinte estava definido: criaríamos um evento no Facebook, convidaríamos nossa rede de contatos e pediríamos que fizessem o mesmo com a sua - e assim por diante. [...] Vamos chamar essa legião de indignados para 'bater panela' em algum lugar juntos (Ibid., p. 36-37).

Assim surge a página do movimento no Facebook e um evento marcado para o dia 16 de outubro de 2014, às 18 horas no Largo da Batata, em São Paulo. Os autores contam que nessa manifestação apareceram cem policiais, devido ao grande número de confirmados para o evento e um aviso por parte da organização à corporação. O princípio da manifestação era o de "tirar o PT do poder", assim, com data de dias antes do segundo turno das eleições, a primeira manifestação teve um teor contra a corrupção e principalmente antipetista. Dentre os acontecimentos nessa primeira manifestação, chama a atenção o fato de se juntarem a um grupo em campanha para o candidato da oposição, Aécio Neves. Segundo a redação do jornal Folha de S. Paulo (2014), a manifestação contou com cerca de 300 pessoas. Essas características (desde a união e participação de membros da oposição às manifestações, mas principalmente a polarização PT x anti-PT) se tornam marcas dessas manifestações, no que Tatagiba e Galvão (2019, p. 66) afirmam ser o "eixo estruturador do confronto político entre os atores relevantes no pós 2013".

Segundo Chequer e Butterfield (2016), além da manifestação em São Paulo, ocorreram outras também em Teresina, Recife e Brasília. Após essa manifestação do dia 16, o grupo de apoiadores cresceu e outra manifestação foi marcada para o dia 22 de outubro daquele ano, passando de quatro cidades para nove com protestos ocorrendo no mesmo dia. O movimento cresceu e recebeu apoio de personalidades famosas, com presenças na manifestação do dia 22. “José Serra, Floriano Pesaro, o ex-jogador de futebol Ronaldo Fenômeno, a cantora Wanessa Camargo, entre outras personalidades" (CHEQUER, BUTTERFIELD, 2016, p. 55-60), além de Fernando Henrique Cardoso. Os autores ainda afirmam que "pelos nossos cálculos, reunimos 25 mil pessoas só em São Paulo" e "levamos nove cidades às ruas: São Paulo, Ribeirão Preto (SP), Belo Horizonte 
(MG), Curitiba (PR), Rio de Janeiro (RJ), Brasília (DF), Recife (PE), Fortaleza (CE) e Teresina (PI). Já era mais que o dobro da saída do dia 16".

Com o sucesso do dia 22, a organização do movimento decide marcar uma outra manifestação para o dia 25 de outubro, no dia anterior ao segundo turno das eleições para Presidente da República. "A manifestação do dia 25 aconteceu em mais de 200 cidades. E repercutiu nos principais veículos da imprensa nacional, ainda que relacionada à defesa de Aécio" (CHEQUER, BUTTERFIELD, 2016, p. 70). Porém, mesmo com todos esses acontecimentos, no dia 26 de outubro a Presidente Dilma Rousseff (PT) foi eleita para o segundo mandato.

Apesar do desânimo dos organizadores por não conquistarem os objetivos iniciais do movimento, que era impedir a vitória da candidata petista, no mês de novembro de 2016 ocorreram mandatos de prisão, busca e apreensão em várias empresas pelo país, realizados pela Polícia Federal em decorrência da Operação Lava Jato, que investiga casos de corrupção e desvio de verbas públicas. Por conta disso, o movimento marcou uma nova manifestação para o dia 15 de novembro, com a bandeira da luta contra a corrupção.

De certa forma, esse foi um segundo nascimento do Vem Pra Rua. [...] Foram 15 mil pessoas às ruas. Essa manifestação nos trouxe muita alegria. Caminhamos da frente do Masp, na Avenida Paulista, até a praça da Sé, no centro de São Paulo. Estávamos ali por uma causa muito maior do que batalhar por um resultado nas eleições. E isso era histórico (CHEQUER, BUTTERFIELD, 2016, p. 79).

Visto o sucesso da manifestação, uma outra foi marcada para o dia 6 de dezembro, a última daquele ano de 2014. Para essa manifestação, diversas personalidades manifestaram apoio, artistas e políticos, porém ela teve pouca adesão popular, fazendo com que a organização optasse por fazer uma parada nas manifestações.

Com o passar do tempo novas denúncias apareceram, a Operação Lava Jato se desenvolveu e outros movimentos entraram em cena, o que levou à organização de uma outra manifestação, no dia 15 de março de 2015. Gohn (2016, p. 141-142) afirma que "O apelo à participação da população na manifestação de 15 de março se fez baseado em critérios e valores morais, apelo à ética, contra a corrupção e não ao passado de luta e militância dos participantes." Segundo a redação da Folha de S. Paulo (2015) e Rossi, Bedinelli e Jiménez (2015), a manifestação em São Paulo contou com cerca de 210 mil manifestantes, além de ocorrerem outras manifestações espalhadas por todos os 26 estados e o Distrito Federal, em pelo menos 152 municípios, incluindo todas as capitais. Gohn (2016) 
aponta para a polêmica acerca da quantidade de manifestantes dessa manifestação, pois enquanto o Datafolha divulgou o número mostrado nas reportagens, de 210 mil manifestantes só em São Paulo, para a Polícia Militar esse número era de um milhão. Porém a autora afirma que essa foi a maior manifestação medida pelo Datafolha desde as Diretas Já, em 1984.

Acontecimentos políticos marcam o cenário nacional e o pedido de Impeachment de Dilma Rousseff é protocolado, escrito pelos juristas Miguel Reale Júnior e Hélio Bicudo. A partir daí, o Vem Pra Rua, que ainda não havia se manifestado a favor do Impeachment por não ver bases jurídicas para isso, segundo seus fundadores, passa a apoiar a decisão. Marcam uma manifestação para o dia 16 de agosto de 2015. "A manifestação de 16 de agosto foi grande: cerca de 1 milhão de pessoas em todos os estados brasileiros. E nós tínhamos uma grande esperança de que ela empurrasse o impeachment adiante" (CHEQUER, BUTTERFIELD, 2016, p. 131).

Em 2 de dezembro daquele ano o pedido de impeachment é aceito pelo então Presidente da Câmara dos Deputados, Eduardo Cunha. Com isso, uma nova manifestação é marcada. "Queríamos comemorar a apresentação do pedido de impeachment e reanimar o povo. E não haveria jeito melhor do que ir às ruas para fazer isso. Escolhemos um dia e horário simbólicos para comemorar a vitória sobre o PT: dia 13 de dezembro, às 13 horas" (CHEQUER, BUTTERFIELD, 2016, p. 139). Os autores afirmam ainda que sabiam que essa manifestação não seria tão grande como a de 15 de março do mesmo ano, e decidiram então promovê-la como um "esquenta" para uma manifestação em 13 de março de 2016, na qual apostariam alto.

A manifestação de 13 de março contou com a presença de políticos da oposição. Segundo Chequer e Butterfield (2016) eram eles: Geraldo Alckmin, José Serra, Aécio Neves, Ronaldo Caiado, Mendonça Filho, Darcísio Perondi e Carlos Marun. Os autores afirmam ainda que ocorreram manifestações em mais de 300 municípios, e segundo matéria no site da revista Época (2016), mais de 3,3 milhões e pessoas foram às ruas, sendo que São Paulo registrou um número de 500 mil pessoas na Avenida Paulista, segundo o Datafolha. E em 17 de março de 2016 é formada a comissão do impeachment.

Em resumo, as manifestações do segundo período, de 2014 e 2015 (aqui trabalhamos até 2016) são protagonizadas principalmente pelo movimento Vem Pra Rua, conforme apontado por Tatagiba, Trindade e Teixeira (2015), contando ainda com a participação de outros movimentos como o Movimento Brasil Livre (MBL) e o Revoltados Online. Eles se colocam em oposição ao governo e à corrupção, que após as denúncias do mensalão no governo petista em 2005, colocam o Partido dos Trabalhadores no centro dos escândalos. 
Os atos de 2015 e 2016 possuem um caráter mais festivo, com a presença de trioelétricos e carros de som, camisas verde-amarelo, bandeiras, pins e bottons, etc. Essas manifestações demarcam, como Souza (2016) afirma, um radicalismo antipetista, com uma ascensão da direita, como demostram também Sakamoto (2013) e Souza J. (2016), que em oposição ao governo faz uso do dispositivo protesto em demanda à aceitação do pedido de impeachment da presidente Dilma pela Câmara dos Deputados. Para Souza C. (2016), essa radicalização ao antipetismo se dá em duas dimensões: uma na qual os mal feitos da política nacional são vistos como culpa do PT e uma outra dimensão que é a partidária mesmo, com críticas ao partido vindos de setores conservadores da sociedade.

Apesar das diferenças entre os dois períodos aqui trabalhados, concordamos com Bringel e Pleyers (2015) e Tatagiba e Galvão (2019), que tratam ambos os períodos como o mesmo ciclo de protestos, compreendendo "esses protestos como parte de um mesmo processo histórico de mudanças, que abrange dimensões políticas, econômicas e culturais" (TATAGIBA, GALVÃO, 2019, p. 71). Uma outra característica apontada pelas autoras é que, apesar dessas manifestações serem convocadas por movimentos sociais e grupos organizados, ocorre uma grande participação de indivíduos não organizados.

\section{CONSIDERAÇÕES FINAIS}

A internet tem se colocado como principal meio no qual as manifestações foram organizadas em todo o mundo desde 2011, e não diferente aqui no Brasil de 2013 aos dias atuais. Com uma dinâmica mais aberta, ela proporciona uma ampla divulgação das ações adotadas pelos movimentos, assim como uma maior participação do público, diferente dos meios tradicionais de informação (como a TV ou o Rádio), nos quais o espectador assiste de maneira passiva, sem poder opinar sobre o que lhes é passado. A internet traz ainda a possibilidade do contato mais amplo até mesmo geograficamente, não estabelecendo fronteiras territoriais para o que é passado e divulgado por ela. Dessa maneira, os atuais movimentos sociais se utilizam da internet como fonte de organização e divulgação das suas ações. Ao longo do texto pudemos perceber a importância desse mecanismo, sem o qual muito dificilmente as manifestações teriam ocorrido e sido tão amplas.

Temos então a emergência de novos padrões de participação no Brasil, marcados pela organização de atos através da internet e que encontra nas ruas sua legitimação. Um 
caldeirão de insatisfações, conforme afirmam Tatagiba e Galvão (2019) explode em 2013, promovendo o que Bringel e Pleyers (2015) chamam de transbordamento societário, levando uma multidão às ruas em manifestações com demandas focadas em problemas da vida cotidiana (GOHN, 2016) que com o tempo vão se diversificando, ocorrendo nas ruas uma disputa pelo sentido delas (ALONSO, 2017), até uma polarização de demandas antipetistas, conforme vimos neste artigo.

Essas manifestações são organizadas por novos movimentos, que encontram na internet um forte mecanismo para divulgação e convocação das manifestações. Do MPL, principal ator das Jornadas de Junho, ao Vem Pra Rua, um dos principais atores das manifestações de 2014 a 2016. Neste artigo trouxe algumas reflexões e discussões que incorporam minha dissertação de mestrado, como já informado. Aqui não tivemos a pretensão de tecer análises sobre as manifestações, apenas demonstrar como elas ocorreram, alguns fatores e histórico delas, mas também apresentar o Vem Pra Rua e seu papel nas manifestações a partir da visão de seus fundadores principalmente, pois em minha dissertação busquei analisar também o que Messenberg (2017) chamou de cosmovisão dos formadores de opinião dos manifestantes de direita brasileiros.

Diversos caminhos se abrem a partir dessa temática, com abordagens e possibilidades amplas para as questões tanto aqui levantadas como as que se tornam consequência do que foi doravante exposto. Precisamos entender a força que essas manifestações tiveram, entender melhor esses atores, tanto civis como os movimentos responsáveis pela organização, suas bandeiras e modus operandi.

\section{REFERÊNCIAS}

ALONSO, A. A política das ruas: Protestos em São Paulo de Dilma a Temer. Novos Estudos Cebrap, São Paulo, n. especial: Dinâmicas da crise, p. 49-58, 2017.

ALONSO, A.; MISCHE, A. Changing Repertoires and Partisan Ambivalence in the New Brasilian Protests. Bulletin of Latin American Research, v. 36, n. 2, p. 144-159, 2017.

ALZAMORRA, G.; ARCE, T.; UTSCH, R. Acontecimentos agenciados em rede: Os eventos do Facebook no dispositivo protesto. In: SILVA, R. H. A. (Org.). Ruas e redes: dinâmicas dos protestos BR. Belo Horizonte: Autêntica Editora, 2014. p. 39-66.

BRINGEL, B.; PLEYERS, G. Junho de 2013... dois anos depois. Polarização, impactos e reconfiguração do ativismo no Brasil. Revista Nueva Sociedad. Buenos Aires. p. 4-17, 2015. 
CASTELLS, M. A galáxia da internet: Reflexões sobre a internet, os negócios e a sociedade. Rio de Janeiro: Zahar, 2003.

Redes de indignação e esperança: movimentos sociais na era da internet. Rio de Janeiro: Zahar, 2013.

CHEQUER, R.; BUTTERFIELD, C. Vem pra rua: a história do movimento popular que mobilizou o Brasil. São Paulo: Matrix, 2016.

FOLHA DE SÃO PAULO. Manifestantes pró-Aécio fazem protesto em São Paulo. 2014.

Disponível em: https://www1.folha.uol.com.br/poder/2014/10/1533733-nao-sabem-votardiz-manifestante-pro-aecio-sobre-o-nordeste.shtml. Acesso em: 01 de set. 2018.

Protestos contra o governo reúnem quase 1 milhão pelo país. 2015.

Disponível em: https://www1.folha.uol.com.br/poder/2015/03/1603286-protestos-contra-ogoverno-reune-quase-1-milhao-pelo-pais.shtml. Acesso em: 01 set. 2018.

GARCIA, F. D. F.; LOPES, C. S. As manifestações de agosto de 2015 em Londrina: aproximações e distanciamentos entre movimentos sociais e manifestantes. Anais do $41^{\circ}$ Encontro Anual da ANPOCS, Caxambu, GT11: Entre as Ruas e os Gabinetes: institucionalização e contestação nos movimentos sociais, 2017.

GOHN, M. G. M. Manifestações de protesto nas ruas no Brasil a partir de Junho de 2013: novíssimos sujeitos em cena. Revista Diálogo Educacional, v. 16, n. 47, p. 125-146, 2016.

LIMA, V. A. de. Mídia, rebeldia urbana e crise de representação. In: MARICATO, E. et al. Cidades rebeldes: Passe Livre e as manifestações que tomaram as ruas do Brasil. São Paulo: Boitempo, Carta Maior. 2013. p. 89-94.

MESSENBERG, D. A direita que saiu do armário: a cosmovisão dos formadores de opinião dos manifestantes de direita brasileiros. Revista Sociedade e Estado, v. 32, n. 3, 2017.

MOVIMENTO BRASIL LIBRE (MBL). MBL - Movimento Brasil Livre. [s.d.]. Disponível em: https://www.facebook.com/pg/mblivre/about/?ref=page_internal. Acesso em: 01 set. 2018.

Movimento passe livre. [s. d.]. Disponível em: https://www.mpl.org.br/. Acesso em: 11 ago. 2020.

NOGUEIRA, M. A. As ruas e a democracia: ensaios sobre o Brasil contemporâneo. Brasília: Fundação Astrojildo Pereira. Rio de Janeiro: Contraponto, 2013.

PESSOA, S. C. A marcha nas ruas e o movimento nas redes: Autocomunicação de massa e mise em scène. In: SILVA, R. H. A. (Org.). Ruas e redes: dinâmicas dos protestos BR. Belo Horizonte: Autêntica Editora, 2014. p. 67-88. 
REDAÇÃO ÉPOCA. As manifestações de 13 de março em todo o Brasil. 2016. Disponível em: https://epoca.globo.com/tempo/noticia/2016/03/manifestacoes-de-13-demarco-em-todo-o-brasil-acompanhe.html. Acesso em: 01 set. 2018.

ROLNIK, R. Apresentação - As vozes das ruas: as revoltas de junho e suas interpretações. In: MARICATO, E. et al. Cidades rebeldes: Passe Livre e as manifestações que tomaram as ruas do Brasil. São Paulo: Boitempo, Carta Maior. 2013. p. 7-12.

ROMÃO, W. de M. \#naovaitercopa: manifestações, Copa do Mundo e as eleições de 2014. Revista de Discentes de Ciência Política da UFSCAR, v. 1, n. 2, 2014.

ROSSI, Marina; BEDINELLI, Talita; JIMÉNEZ, Carla. Uma multidão protesta contra o Governo Dilma: São Paulo domina os protestos que pedem o impeachment da presidenta. 2015. Disponível em: https://brasil.elpais.com/brasil/2015/03/15/politica/1426458992_617989.html. Acesso em: 01 set. 2018.

SAKAMOTO, L. Em São Paulo, o Facebook e o Twitter foram às ruas. In: MARICATO, E. et al. Cidades rebeldes: Passe Livre e as manifestações que tomaram as ruas do Brasil. São Paulo: Boitempo, Carta Maior. 2013. p. 95-100.

SECCO, L. As jornadas de junho. In: MARICATO, E. et al. Cidades rebeldes: Passe Livre e as manifestações que tomaram as ruas do Brasil. São Paulo: Boitempo, Carta Maior. 2013. p. 71-78.

SINGER, A. Brasil, Junho de 2013: classes e ideologias cruzadas. Novos Estudos Cebrap, n. 97, p. 23-40. 2013.

SOUZA, C. A. de. Antipetismo e ciclos de protestos no Brasil: Uma análise das manifestações ocorridas em 2015. Em Debate, Belo Horizonte, v. 8, n. 3, p. 35-51, 2016. SOUZA, J. A radiografia do golpe: entenda como e por que você foi enganado. Rio de Janeiro: LeYa, 2016.

TATAGIBA, L. 1984, 1992 e 2013. Sobre ciclos de protestos e democracia no Brasil. Política e Sociedade. v.13, n. 28, 2014.

TATAGIBA, L.; TRINDADE, T. e TEIXEIRA, A. C. C. Protestos à direita no Brasil (20072015). In: CRUZ, S. V.; KAYSEL, A.; CODAS, G. (Orgs). Direita, volver!: o retorno da direita e o ciclo político brasileiro. São Paulo: Editora Fundação Perseu Abramo, 2015. p. 197-212.

TATAGIBA, L.; GALVÃO, A. Os protestos no Brasil em tempos de crise (2011-2016). Opinião Pública, Campinas, v. 25, n. 1, p. 63-96, 2019.

VEM PRA RUA. O movimento. [s.d.]. Disponível em: https://www.vemprarua.net/omovimento/\#vem-pra-rua. Acesso em: 01 set. 2018.

Manifesto. [s.d.]. Disponível em: https://www.vemprarua.net/omovimento/manifesto.html. Acesso em: 01 set. 2018. 


\section{YORUK, E. O longo verão da Turquia: Entendendo o levante de Gezi. Novos Estudos}

Cebrap, n. 97, p. 57-66, 2013.

\section{NOTAS}

\section{TÍTULO DA OBRA}

Manifestações brasileiras e o Movimento Vem Pra Rua: breve análise dos acontecimentos

\section{Vinícius de Souza Sturari}

Mestre em Ciências Sociais

Universidade Estadual Paulista "Júlio de Mesquita Filho" - UNESP, Faculdade de Ciências e Letras de Araraquara (FCLAr), Araraquara, Brasil

v.sturari@gmail.com

(D) https://orcid.org/0000-0003-0727-770X

LICENÇA DE USO - uso exclusivo da revista

Os autores cedem à Em Tese os direitos exclusivos de primeira publicação, com o trabalho simultaneamente licenciado sob a Licença Creative Commons Attribution 4.0 Internacional (CC BY). Estra licença permite que terceiros remixem, adaptem e criem a partir do trabalho publicado, atribuindo o devido crédito de autoria e publicação inicial neste periódico. Os autores têm autorização para assumir contratos adicionais separadamente, para distribuição não exclusiva da versão do trabalho publicada neste periódico (ex.: publicar em repositório institucional, em site pessoal, publicar uma tradução, ou como capítulo de livro), com reconhecimento de autoria e publicação inicial neste periódico.

PUBLISHER - uso exclusivo da revista

Universidade Federal de Santa Catarina. Programa de Pós-Graduação em Sociologia Política. Publicado no Portal de Periódicos UFSC. As ideias expressadas neste artigo são de responsabilidade de seus autores, não representando, necessariamente, a opinião dos editores ou da universidade.

HISTÓRICO - uso exclusivo da revista

Recebido em: 31 de maio de 2020

Aprovado em: 17 de agosto de 2020 